\title{
RELAÇÃO PESO-COMRIMENTO DE TAINHAS (Mugil spp.) NA COSTA DA \\ BAHIA
}

\section{Mydian Cristiane da Rocha Santos'; Alexandre Clistenes de Alcântara Santos ${ }^{2}$;}

1. Bolsista PROBIC, Graduando em Bacharelado em Ciências Biológicas, Universidade Estadual de Feira de Santana, e-mail: mydi07@ hotmail.com

2. Orientador, Departamento de Ciências Biológicas, Universidade Estadual de Feira de Santana, e-mail: alexandreclistenes@gmail.com

PALAVRAS-CHAVE: Mugil (sp); Costa da Bahia; peso-comprimento;

\section{INTRODUÇÃO}

Ambientes costeiros, como estuários, lagoas e baías são essenciais ao desenvolvimento dos recursos pesqueiros de importância econômica e ambiental, tendo em vista o seu papel no desempenho dos ciclos biológicos, atuando como berçários, tanto de espécies características desses ambientes como de outras marinhas que migram para essas áreas durante a fase reprodutiva. As Tainhas (Mugil spp.) são peixes costeiros, que formam cardumes, encontrados em grande abundância e em sua maioria em ambientes estuarinos. $\mathrm{O}$ pouco conhecimento em relação ao ciclo de vida das tainhas em regiões tropicais leva a necessidade de realização de estudos sobre diferentes aspectos de sua biologia e ecologia.

Parte-se do pressuposto que o conhecimento de aspectos quantitativos, como a relação peso-comprimento, de determinada espécie de peixe, é de grande importância para o desenvolvimento de estudos da biologia pesqueira, fazendo-se necessária para o manejo e preservação do ambiente, ao mesmo tempo em que coloca em evidência informações sobre a autoecologia das espécies Lizama \& Ambrósio (2003); Vazzoler. (1982). Além desta relação, o fator de condição é outro indicativo quantitativo importante, aonde se refletem as condições alimentares recentes do peixe, podendo ser afetado pela idade, meio ambiente, sexo e outros fatores Le Cren (1951).

\section{MATERIAL E MÉTODOS OU METODOLOGIA (ou equivalente)}

O presente trabalho foi realizado em três importantes áreas estuarinas do litoral baiano. Ilha de Itaparica localizada na Baía de Todos os Santos, estuário de Caravelas inserido na chamada Costa Leste Brasileiro.

Os adultos de tainha foram obtidos a partir de amostragens nos desembarques pesqueiros e coletas em áreas profundas utilizando linha e rede de arrasto de fundo. Os 
juvenis foram coletados nas zonas rasas dos estuários, utilizando redes de arrasto manual (tipo picaré), durante as marés de sizígia. Os peixes capturados foram acondicionados em gelo e em laboratório triados, medidos, pesados e identificados segundo a literatura corrente. Material testemunho foi sendo depositado na coleção científica da Divisão de Peixes do a Museu de Zoologia da UEFS. Para as análises de distribuição e abundância relativa utilizou-se o número de indivíduos por arrasto (CPUEs) e gramas por arrasto (biomassa). As espécies identificadas foram agrupadas conforme o local de coleta, facilitando a comparação do seu comprimento total por meio de gráficos. O cálculo da relação peso-comprimento foi realizado através da equação potencial de Huxley, descrita por $W=a L^{\mathrm{b}}$, onde o W é igual ao peso, L é o comprimento, b é a potência do peso e a é a constante Krug (1998).

\section{RESULTADOS E/OU DISCUSSÃO (ou Análise e discussão dos resultados)}

O comprimento total de Mugil brevirostris variou entre 20 e $110 \mathrm{~mm}$, tendo o maior número de indivíduos no intervalo de 40-50 mm. Entre os espécimes de Mugil curema, o comprimento total variou entre 20 e $162 \mathrm{~mm}$, possuindo maior número de indivíduos com o comprimento total no intervalo entre 20-40 mm. Os espécimes de Mugil curvidens obtiveram como variação de comprimento total 130 e $262 \mathrm{~mm}$, sendo os maiores obtidos nas amostragens. Em Mugil liza o comprimento total variou entre 22 e $96 \mathrm{~mm}$, possuindo maior número de indivíduos no intervalo de 30-40 mm. Nos espécimes de Mugil sp o comprimento total variou entre 2,5 e $103 \mathrm{~mm}$, possuindo maior número de indivíduos no intervalo de 20-30 mm (Figura 1).

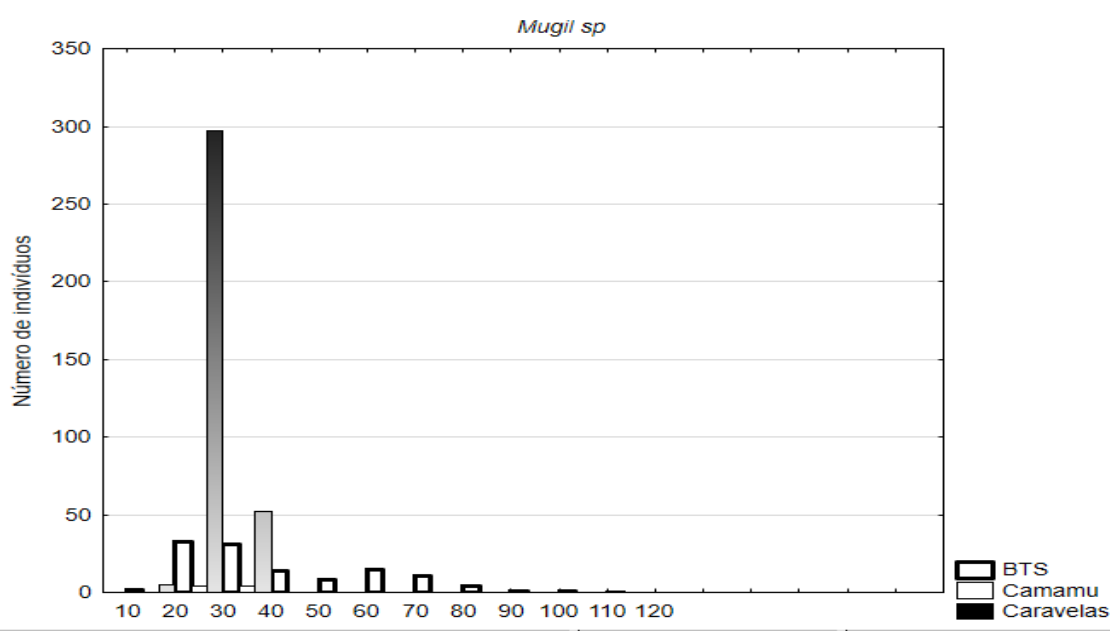

Figura 1- Distribuição dos espécimes de Mugil sp conforme seu comprimento total e o número de indivíduos, coletados na Baía de Todos os Santos, Baía de Camamu e Baía de Caravelas. 
$\mathrm{Na}$ relação peso-comprimento, cada espécie obteve curvas de potência diferentes conforme o local de coleta. Em Mugil brevirostris, os espécimes coletados da Baía de Camamu, foram insuficientes para formar uma curva de potência como as de Caravelas e Baía de Todos os Santos, sendo a única que obteve $\mathrm{R}^{2}$ (coeficiente de correlação) igual a 1 (Figura 2). O mesmo aconteceu com os espécimes de Mugil liza coletados na Baía de Camamu, apresentando o mesmo valor de $\mathrm{R}^{2}$ igual a 1 .
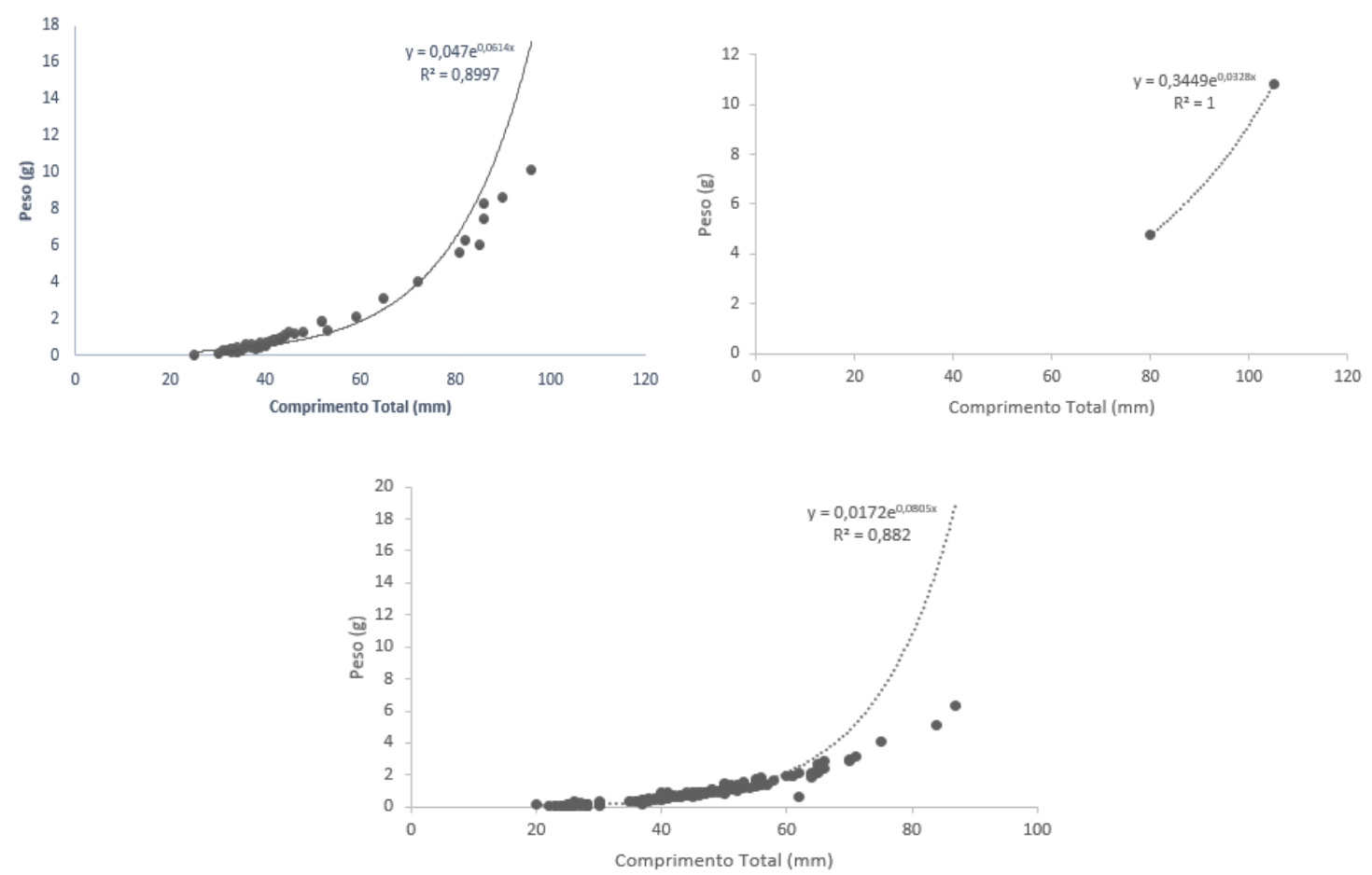

Figura 2- Relação peso-comprimento de Mugil brevirostris

Os espécimes de Mugil sp coletados na Baía de Caravelas apresentaram um padrão de distribuição muito diferente daqueles constatados nas outras espécies, isso se deve ao fato de que maior parte dos indivíduos coletados são provenientes de arrastos pesqueiros, usando outros equipamentos que indiretamente selecionam o tamanho destes indivíduos e permite que os de menor comprimento não sejam capturados com maior frequência. Através dos valores encontrados para as espécies de Mugil curema, foi possível observar o melhor desenvolvimento nos indivíduos coletados na Baía de Caravelas, possuindo o valor de $\mathrm{R}^{2}$ próximo de 1 . Para todas as espécies o valor de $\mathrm{b}$ foi menor do que três, indicando que todas possuem um crescimento alométrico, ou seja, a taxa de crescimento ocorre de forma desigual em todas as dimensões Krug (1998). A diferença na distribuição nos locais de coletas pode ser motivada pelas condições bióticas e abióticas que variam entre as Baías. 
Através do presente trabalho é possível concluir que cada espécie apresenta comportamento diferente nos respectivos locais da amostragem, sendo os maiores indivíduos encontrados na Baía de Caravelas. As realizações de outras análises são necessárias para entender e quantificar os fatores que favorecem o desenvolvimento de cada espécie nas Baías.

\section{REFERÊNCIAS}

LE CREN, E.D. The length - weight relationship and seasonal cycle in gonad weight and condition in the perch (Perca fluviatilis). J. Anim. Ecol., Oxford, v. 20, p. 201-219, 1951

LIZAMA, M. de los A.P.; AMBRÓSIO, A.M. Condition factor in nine species of fish of the Characidae family in the upper Paraná river floodplain, Brazil. Braz. J. Biol., São Carlos, v. 62, n. 1, p. 113-124, 2002.

KNOX GA (2000). The ecology of seashores. CRC Press. 544p.

KRUG, L. C. 1998. Manual da Disciplina de Biologia Pesqueira. 22 p.

RODRIGUEZ-ROMERO, J.; Abitia-Cárdenas, L. A.; Galván-Magaña, F.;ChávezRamos, H. 1994. Composicion, abundancia y riqueza es- pecifica de la ictiofauna de Bahia Conception, Baja Califórnia sur,México.Ciências Marinas, 20. (3): 321-350.

ZAVALA-CAMIN, L. A. (1996). Introdução aos estudos sobre alimentação natural em peixes. Maringá: EDUEM. 129p.

NELSON, J.S., 1994. Fishes of the world. Third edition. John Wiley \& Sons, Inc., New York. 600 p.

PAYNE, A.L. 1986. The ecology of tropical lakes and rivers. Jonh Wiley \& Sons, New York

SANTOS, E.P. Dinâmica de populações aplicada à pesca e piscicultura. São Paulo: Hucitec (Edusp), 1978.

SILVA, J. T. O. 2004. Ictiofauna das praias de Cabuçu e Berlinque: Uma análise comparativa de comunidade de peixes na Baía de Todos os Santos. Dissertação de mestrado do curso de posgraduação em ecologia e biomonitoramento UFBA. 92p.

VANZOLINI, P.E. Métodos estatísticos elementares em sistemática zoológica. São Paulo: Ed. Hucitec, 1993.

VAZZOLER, A.E.A.M. Biologia da reprodução de peixes teleósteos: teoria e prática. 